\section{SHUMIN FENG}

Shumin Feng, Ph.D.

E-mail: zlyfsm2000@sina.com

HAIYUE WU,

(Corresponding author)

E-mail:wu1103200105@sina.com

XIANGLONG SUN, Ph.D.

E-mail: sunxianglong001@163.com

ZHENNING LI

E-mail: 18686723116li@gmail.com

School of Transportation Science and Engineering

Harbin Institute of Technology

Harbin, 150090, China
Human - Transport Interaction

Preliminary Communication

Submitted: Jan. 21, 2015

Accepted: Sep. 29, 2015

\title{
FACTORS OF PERCEIVED WAITING TIME AND IMPLICATIONS ON PASSENGERS' SATISFACTION WITH WAITING TIME
}

\begin{abstract}
In order to explore the influence factors on perceived waiting time, a multiple linear regression model has been used to quantitatively describe the relationship between perceived waiting time and various factors. The model is established with 234 data, which is surveyed with questionnaire at three stops in Harbin, China. The results show that several certain factors ("trip purpose - where to", "presence of a companion - whether one has a companion or not", "having a timing device - whether one has a timing device or not", "riding frequency - how many times one takes one line per week" and "waiting behaviour - what one does while waiting for a bus") have significant influence on perceived waiting time, which confirms previous findings and supports transferability of results. The significance of "waiting mood - how about the mood while waiting for a bus" and "reserved waiting time - how long one will wait" are confirmed for the first time in this study. In contrast to previous studies, "waiting time interval - for how long in one day" is a negative variable and socioeconomic variables are non-significant. And it is found that the relationship between perceived waiting time and passengers' satisfaction with the waiting time follows a decreasing exponential distribution. With this model, the variation trend of the section, where passenger satisfaction value is larger than 0 is obviously steeper than the section smaller than 0 . Such result proves that passenger mood with short waiting time is more sensitive than with longer waiting time. And the borderline perceived waiting time, distinguishing satisfied from dissatisfied passengers is proven to be 7.87 minutes when assignment interval of satisfaction is (-25.25], when satisfaction is positive (larger than 0), the accuracy being $70.30 \%$, while the accuracy is $82.71 \%$ for negative satisfaction (less than 0 ).
\end{abstract}

\section{KEY WORDS}

perceived waiting time; linear regression model; passenger satisfaction with waiting time; borderline perceived waiting time;

\section{INTRODUCTION}

Urban conventional bus transportation provides sustainable and fair service at a low travel cost for passengers; however, the share in Harbin, Heilongjiang Province is far lower than private cars, which is mainly attributed to crowded traffic in rush hour, unstable headway and poor vehicle interior comfort. Moreover, Psarros et al. [1] found that the abovementioned reasons would lead to low passengers' satisfaction with waiting time. Some scholars have pointed out that the key to improving the attraction of public transportation was the improvement of passenger perception [2]. In recent years, traffic planners have increasingly focused on improving service quality and passengers' satisfaction in the design and improvement stage of public transportation systems [3, 4].

The passenger perceptions of bus service can be described in terms of passengers' satisfaction with waiting time, and it is affected by many factors. Hensher [5] identified two factors, waiting environment service quality and information service quality. Then Stopher et al. [6] extended this research and found that the most influential factors were punctuality rate of buses' arrival, walking time from the origin to destination bus stop, and service facilities of the bus stop. Wen et al. [7] used variable stepwise elimination and determined that the predominant factors were passengers' waiting time and passenger waiting behaviour. Das and Pandit [8] proved that shortening of passenger waiting time could indirectly improve passenger satisfaction and ultimately improve bus capacity. While the time cost indicated that customers preferred to wait rather than to pay for more frequent service, the management's goal was to provide the most suitable service for passengers, thus a more frequent bus timetable was necessary. However, this brought high costs; 
otherwise, management had to use other means to make passengers more satisfied in their waiting time [9]. Therefore, based on the perspective of time cost, the perceived waiting time is a relatively important factor for passenger satisfaction. Friman and Gärling [10] established a mathematical model to explore the relationship between passengers' satisfaction and the frequency of major accidents; similarly it is feasible to explore only one important correlated variable which is the perceived waiting time, for passenger satisfaction.

Van Hagen and Galetzka [11] found that passengers' perceived waiting time was often greater than the actual waiting time and that the perception deviation is larger when the actual waiting time is shorter, and then the passengers' negative emotions such as irritability and restlessness grow, and this also influences the passengers' travel quality. Psarros et al. [1] used the continuous time risk model to explore the factors that influence the perceived waiting time and found that "age", "trip purpose" and "travel time" had effects. They also found that the elderly and group trips for work or school would automatically extend the perceived waiting time, and in the morning peak the travel population would automatically shorten the perceived waiting time. Studies have indicated that real-time information could reduce the passenger perceived waiting time, thus Watkins et al. [12] presented a multiple linear regression model including real-time information, riding frequency, peak time and other factors to forecast the waiting time. Hui et al. [13] indicated that passenger psychological changes could be improved in the process of waiting for buses, which would affect the perceived waiting time from two aspects (real-time arrival information and a comfortable waiting environment) and attract passengers' attention. Other passenger factors, such as waiting behaviour and the presence of companions, could produce a deceptive effect and reduce passenger perceived waiting time, while negative emotions could make passengers overestimate their waiting time [11].

At present, the majority of studies on perceived waiting time and passenger satisfaction only used the influencing factors in establishing the related models and they did not take into account the specific relationship between the perceived waiting time and the passenger satisfaction. However, the findings of many scholars indicated that the perceptions of waiting time directly influenced the evaluation of bus service quality, which meant that there was a relationship between the perceived waiting time and passenger satisfaction. At the same time, the results on the influencing factors of perceived waiting time are not uniform. Therefore, this paper will consider more factors to create a model of influencing factors of perceived waiting time and construct a relationship model between perceived waiting time and passenger satisfaction. And because of the limitation of research condition, only bus transport was studied.
This paper is organized as follows. In Section 2 the detailed survey scheme is introduced. In Section 3 a multiple linear regression model is applied for fitting the influence factors of passenger perceived waiting time. In Section 4, the relationship between perceived waiting time and passenger satisfaction based on the exponential distribution model is discussed in detail and results are provided to validate the performance of the proposed approach. Finally, the conclusion and the future work will be presented.

\section{SURVEY}

\subsection{Stop selection principles}

Too many bus lines or too few passengers will affect the efficiency of survey and accuracy of the sample. It is necessary to comply with the following three principles in the process of selecting the bus stops. Firstly, the selected stops cannot serve too many lines. It is best that there are no more than three lines. Waiting passengers could reasonably infer the bus arrival time and estimate whether they have enough time to conduct the survey at the stops. Secondly, passenger arrival should be random which can improve the reliability of the sample data. The third is that the stop must have essential demand to some extent in order to guarantee a sufficient sample size in the finite investigation time.

\subsection{Surveyed stops}

Based on the above selection principles, three stops were selected in Harbin, Heilongjiang Province, China, and a total of ten lines were involved. The basic bus service information of surveyed stops and involved lines are shown in Table 1.

\subsection{Investigation}

Factors of perceived waiting time and passenger satisfaction were surveyed through administering a questionnaire. In addition to passenger basic information, such as gender, occupation and education, the following questions were also assessed in the questionnaire.

1) Having a timing device: Whether you have a timing device or not?

2) Presence of a companion: Whether you have companions or not?

3) Travel purpose: Where you are going? Home, working place, school, shopping or other?

4) Riding frequency: How many times do you ride this line per week?

5) Walking time: How long did it take if you walk to your destination from the surveyed stop instead of riding a bus? 
Table 1 - Basic information of surveyed stops

\begin{tabular}{||c|c|c|c|c|c|c||}
\hline \multirow{2}{*}{ Stop number } & \multirow{2}{*}{$\begin{array}{c}\text { Line quantity } \\
\text { in service }\end{array}$} & \multicolumn{6}{|c|}{ Basic information of involved lines } \\
\cline { 3 - 7 } & & Line number & $\begin{array}{c}\text { Average } \\
\text { headway/min }\end{array}$ & Length/km & $\begin{array}{c}\text { Amount of sites } \\
\text { along line }\end{array}$ & $\begin{array}{c}\text { Average } \\
\text { speed/km/h }\end{array}$ \\
\hline \hline 1 & 3 & 1 & 9 & 16.7 & 32 & 25 \\
\hline & & 2 & 7 & 22.0 & 37 & 25 \\
\hline 2 & 3 & 3 & 9 & 22.7 & 39 & 25 \\
\hline & & 4 & 9 & 17.1 & 31 & 25 \\
\hline 3 & 4 & 6 & 5 & 16.7 & 32 & 25 \\
\hline & & 7 & 5 & 21.9 & 41 & 25 \\
\hline & & 9 & 6 & 10.7 & 21 & 25 \\
\hline & & 10 & 7 & 18.9 & 37 & 25 \\
\hline
\end{tabular}

6) Reserved waiting time: How long is the maximum time that you would be willing to wait?

7) Waiting behaviour: What are you doing in the process of waiting for the bus?

8) Waiting mood: What is your mood now? Very easy, easy, no feeling, anxious or very anxious?

9) Passenger perceived waiting time: What do you think how long did you wait?

10) Satisfaction grade: Please fill out the waitingtime to meet every satisfaction grade, they are very satisfied, satisfied, no feeling, unsatisfied and very unsatisfied (e.g. how many minutes for "very satisfied" do you think?).

In the survey, three minutes were needed on the average for passengers to finish one questionnaire. The investigation was done in time intervals of 7:00-9:00, 12:00-13:00 and 16:30-18:30 on May 18, 2014. There were six investigators that were divided as three groups and each group was in charge of one bus stop. All members had been trained in advance. The investigation was done with nice weather conditions and 40, 20 and 40 questionnaires were distributed, respectively, from the earliest time interval to the last one. All the questionnaires were filled by passengers with the help of trained investigators. The three groups conducted the survey on the same day and obtained 300 questionnaires eventually.

\subsection{Statistical results}

There were 300 questionnaires distributed in this survey, from which the unfinished and unreliable questionnaires were removed, and 234 were valid. The statistical sample data characteristics are shown in Table 2.

As shown in Table 2, the gender ratio is close to 1:1. The number of passengers having a timing device is much larger than those without. The proportion of taking "home" and "work or school" as travel purpose is close to $70 \%$, which is likely to be related to the longer survey time in the morning and evening rush hours. The ratio of riding frequency is close to $1: 1: 1$, and this variable represents the degree of familiarity with bus service. Over $75 \%$ passengers will walk more than 30 minutes if they choose walking rather than taking a bus, which illustrates that the travelling of most people is long-distance. Reserved waiting time is related to the waiting mood when the perceived waiting time is longer than their reserved time passengers seem to become anxious.

\section{INFLUENCE FACTORS OF PERCEIVED WAITING TIME}

\subsection{Model}

In order to synthesize discrete and continuous variables and quantitatively describe the weights of all factors, meanwhile linear regression model is generally selected for psychological behaviour research. Thus eventually a multiple linear regression model was used to explore the various influence factors of perceived waiting time. The model could be described as $y=\beta_{0}+\beta_{1} x_{1}+\beta_{2} x_{2}+\ldots+\beta_{n} x_{n}$ where $y$ is the perceived waiting time, minute, $x(i=1,2, \ldots, n)$ is the influence factors, and $\beta_{k}(k=0,1, \ldots, n)$ is the coefficient.

In order to determine the parameters for modelling, it is necessary to transfer the variables with qualitative description into the quantitative data. So every variable with qualitative description is described as one or zero; for example, if the passenger's "travel purpose" is "home", then the value of variable "travel purpose: home" is one and vice versa other variables in the group of "travel purpose" are zeros, e.g. "travel purpose: working or school" is zero. Among these, "gender" "occupation" "education" "having a timing device" "presence of a companion" "travel purpose" "riding frequency" "waiting behaviour" "waiting mood" and "waiting time interval" use the abovementioned assignment method. While "walking time" and 
S. Feng, H. Wu, X. Sun, Z. Li: Factors of Perceived Waiting Time and Implications on Passengers' Satisfaction with Waiting Time

Table 2 - Descriptive statistics of the sample

\begin{tabular}{|c|c|c|c|}
\hline Variable & Categories & Amounts & Percentage \\
\hline \multirow[t]{2}{*}{ Gender } & Male & 121 & $51.70 \%$ \\
\hline & Female & 113 & $48.30 \%$ \\
\hline \multirow[t]{4}{*}{ Occupation } & Students & 83 & $35.50 \%$ \\
\hline & Office workers & 94 & $40.20 \%$ \\
\hline & Retired & 49 & $30.0 \%$ \\
\hline & Other & 8 & $3.30 \%$ \\
\hline \multirow[t]{4}{*}{ Education } & Junior high school and below & 35 & $14.90 \%$ \\
\hline & Senior high school & 97 & $41.50 \%$ \\
\hline & Undergraduate or specialized & 72 & $30.80 \%$ \\
\hline & Master's or above & 30 & $12.80 \%$ \\
\hline \multirow[t]{2}{*}{ Having a timing device } & Yes & 208 & $88.89 \%$ \\
\hline & No & 26 & $11.11 \%$ \\
\hline \multirow[t]{2}{*}{ Presence of a companion } & Yes & 89 & $38.03 \%$ \\
\hline & No & 145 & $61.97 \%$ \\
\hline \multirow[t]{4}{*}{ Travel purpose } & Home & 62 & $26.50 \%$ \\
\hline & Work or School & 97 & $41.45 \%$ \\
\hline & Shopping or Entertainment & 50 & $21.37 \%$ \\
\hline & Other & 25 & $10.68 \%$ \\
\hline \multirow[t]{3}{*}{ Riding frequency (per week) } & $1-5$ & 78 & $33.33 \%$ \\
\hline & $6-10$ & 80 & $34.19 \%$ \\
\hline & $>10$ & 76 & $32.48 \%$ \\
\hline \multirow[t]{6}{*}{ Walking time/min } & $\leq 20$ & 12 & $5.13 \%$ \\
\hline & $21-30$ & 45 & $19.23 \%$ \\
\hline & $31-40$ & 56 & $23.93 \%$ \\
\hline & $41-50$ & 57 & $24.36 \%$ \\
\hline & $51-60$ & 37 & $15.81 \%$ \\
\hline & $>60$ & 27 & $11.54 \%$ \\
\hline \multirow[t]{5}{*}{ Reserved waiting time/min } & $\leq 5$ & 32 & $13.68 \%$ \\
\hline & $6-10$ & 121 & $51.71 \%$ \\
\hline & $11-15$ & 49 & $20.94 \%$ \\
\hline & $16-20$ & 21 & $8.97 \%$ \\
\hline & $>20$ & 11 & $4.70 \%$ \\
\hline \multirow[t]{4}{*}{ Waiting behaviour } & Using electronic equipment & 73 & $31.20 \%$ \\
\hline & Chatting with companion & 71 & $30.34 \%$ \\
\hline & Nothing & 88 & $37.61 \%$ \\
\hline & Other & 2 & $0.85 \%$ \\
\hline \multirow[t]{5}{*}{ Waiting mood } & Very easy & 14 & $5.98 \%$ \\
\hline & Easy & 51 & $21.79 \%$ \\
\hline & No feeling & 80 & $34.19 \%$ \\
\hline & Anxious & 60 & $25.64 \%$ \\
\hline & Very anxious & 29 & $12.39 \%$ \\
\hline \multirow[t]{3}{*}{ Waiting time interval } & Morning peak & 85 & $36.32 \%$ \\
\hline & Off-peak & 48 & $20.51 \%$ \\
\hline & Evening peak & 101 & $43.16 \%$ \\
\hline
\end{tabular}


"reserved waiting time" are originally quantitative data, the raw survey data are satisfactory.

\subsection{Parameters of the model and analysis}

SPSS software was chosen to fit linear regression model. These survey variables are likely to be related, which is the concept of multicollinearity. The variable with multicollinearity should be removed. So the method of eliminating backwards was chosen to eliminate unsuitable variables. The results are shown in Table 3. Significant level should be less than 0.05 for significant variables.

Table 3 shows the results excluding the variables with multicollinearity. The "occupation" variable did not appear in it, which suggests that it is a variable with multicollinearity. And according to significant level, it is obvious that "gender" "education" and "walking time" have less significance and "having a timing device" "presence of a companion" "trip purpose" "riding frequency" "waiting mood" "waiting behaviour" "waiting time interval" and "reserved waiting time" have good significance.

In order to improve the precision of the model, the paper eliminates the less significant variables in Table 3. The model was refitted and the results are shown in Table 4.

Perceived waiting time can be described by Equation 1:

$$
\begin{aligned}
y= & 7.604-1.526 x_{W T}-1.474 x_{W C}+1.545 x_{T P}+ \\
& +1.054 x_{R F}+0.894 x_{R W}-0.027 x_{R W} \\
& -1.104 x_{B C}+1.781 x_{M A}+2.866 x_{M W}
\end{aligned}
$$

Table 3 shows that the perceived waiting time is well correlated with "waiting mood", which indicates that poor mood will extend the perceived waiting time. "Trip purpose for work or school" and "morning peak" are positively correlated with perceived waiting time.

Table 3 - Estimation results after eliminating variables with multicollinearity

\begin{tabular}{||l|c|c||}
\hline \multicolumn{1}{|c|}{ Variable } & \multicolumn{2}{c||}{ Standard coefficient } \\
\cline { 2 - 3 } & B & Sig. \\
\hline \hline (Constant) & 8.403 & 0.000 \\
\hline Gender: Female & -0.485 & 0.436 \\
\hline Education: Master's or higher & -0.752 & 0.460 \\
\hline Having a timing device & -0.526 & 0.048 \\
\hline Presence of a companion & -1.502 & 0.033 \\
\hline Travel purpose: work or school & 1.744 & 0.041 \\
\hline Riding frequency: >10 times/week & 1.056 & 0.044 \\
\hline Walking time & -0.017 & 0.351 \\
\hline Reserved waiting time & 0.027 & 0.023 \\
\hline Waiting behaviour: chat with companion & -1.056 & 0.049 \\
\hline Waiting mood: anxious & 1.864 & 0.016 \\
\hline Waiting mood: very anxious & 3.005 & 0.003 \\
\hline Waiting time interval: morning peak & 1.094 & 0.039 \\
\hline Waiting time interval: evening peak & $0.537 s$ & 0.029 \\
\hline \hline
\end{tabular}

Table 4 - Estimation results after eliminating variables with less significance

\begin{tabular}{||l|c|c||}
\hline \multicolumn{1}{|c|}{ Variable } & \multicolumn{2}{c||}{ Standard coefficient } \\
\cline { 2 - 3 } & B & Sig. \\
\hline \hline (Constant) & 7.604 & 0.000 \\
\hline Having a timing device $x_{W T}$ & -1.526 & 0.047 \\
\hline Presence of a companion $x_{W C}$ & 1.474 & 0.050 \\
\hline Travel purpose: work or school $x_{T P}$ & 1.545 & 0.041 \\
\hline Riding frequency: $>10$ times/week $x_{R F}$ & 1.054 & 0.048 \\
\hline Waiting time interval: morning peak $x_{T M}$ & 0.894 & 0.047 \\
\hline Reserved waiting time $x_{R W}$ & 0.027 & 0.036 \\
\hline Waiting behaviour: chat with companion $x_{B C}$ & -1.104 & 0.042 \\
\hline Waiting mood: anxious $x_{M A}$ & 1.781 & 0.014 \\
\hline Waiting mood: very anxious & 2.866 & 0.003 \\
\hline
\end{tabular}


"Riding frequency" is positively correlated with perceived waiting time. The passengers riding a bus with higher frequency may have a better understanding about the arrival time of the bus, enabling a shorter waiting time. "Having a timing device" is a negatively correlated variable which shows that if the stops are equipped with clocks or real-time information board, passenger perception of waiting time will decrease. "Presence of a companion" is a negatively correlated variable. It can relieve the passenger tension and reduce the perception of waiting time. A positive correlation was found between "reserved waiting time" and perceived waiting time, which means that the longer a passenger's reserved waiting time is, the larger is the perceived deviation.

"Trip purpose", "with companion", "riding frequency" and "waiting behaviour" were found having significant influences on the perceived waiting time. The result was in line with the previous model $[1,11,12]$. Several studies proposed that "waiting mood" and "reserved waiting time" may influence perceived waiting time, and this paper verified the significant influence of these factors [9, 13]. In addition, one study has shown that education, occupation, and other basic factors have significant influences on perceived waiting time [1]. However, these relationships in this research were not proven, which is possibly caused by different environment and sample limitation, for example, urban traffic land is more compact and urban residential population is more intensive in China than those in foreign countries.

\section{PASSENGER SATISFACTION WITH WAITING TIME}

\subsection{Quantitatively described waiting satisfaction}

The level of satisfaction was divided into five grades: very satisfied, satisfied, no feeling, dissatisfied, very dissatisfied. According to question 10 in sec- tion 2.3, every surveyed passenger filled in an acceptable waiting time for different grades of satisfaction, and the waiting time interval from "very satisfied" to "very dissatisfied" was 0-50 min. In order to explore the quantitative relationship between waiting time and passenger satisfaction, the qualitative descriptions of the five moods have been converted into quantitative descriptions. Fifty was selected as the width of assignment range, and finally $(-25,25]$ was chosen as the assignment range to be consistent with the symmetry distribution regularity of the satisfaction grade. Each grade corresponded to 234 samples, in order to improve precision of model, this paper ascertained 10 sets of values through dividing the lower and upper limits. The assignment method is shown in Table 5.

To simplify things, integer values in each interval were randomly selected for corresponding passenger satisfaction. There were 234 samples input into MATLAB. The software could realize discrete data serialization, and the relation curve was obtained when data were imported and the result is shown in Figure 1.

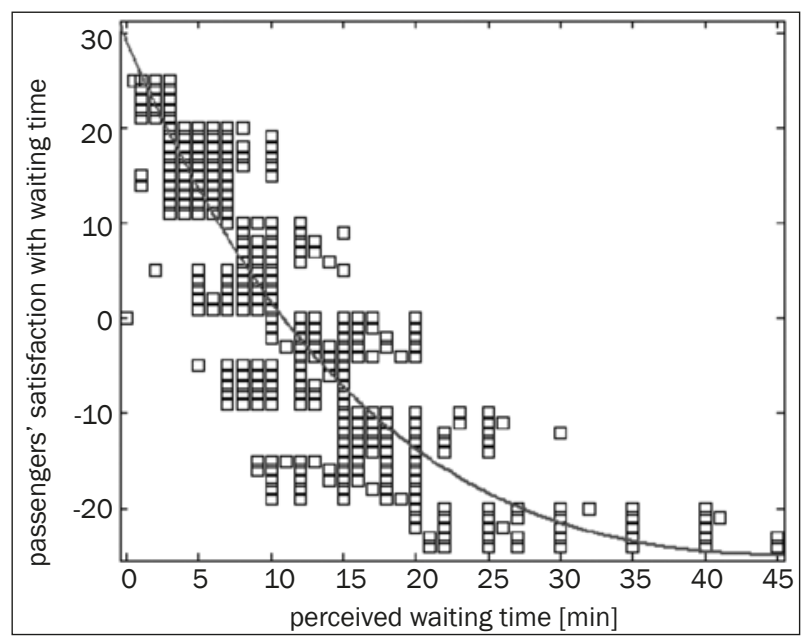

Figure 1- Scatter diagram of the 234-sample data Scatter diagram perceived waiting time

Table 5 - Value intervals corresponding to different grades of satisfaction

\begin{tabular}{||c|c|c||}
\hline Waiting satisfaction grade & & Value interval \\
\hline \hline Very dissatisfied & The lower & $(-25,-20]$ \\
\hline Dissatisfied & The upper & $(-15 .-10]$ \\
\hline & The lower & $(-10,-5]$ \\
\hline No feeling & The upper & $(-5,0]$ \\
\hline & The lower & $(0,5]$ \\
\hline Satisfied & The upper & $(10,15]$ \\
\hline & The lower & $(15,20]$ \\
\hline Very satisfied & The upper & $(20,25]$ \\
\hline
\end{tabular}


The curve indicates the input data points fitted curve. According to the curve shape, an exponential distribution model is used to describe the relationship between perceived waiting time and passengers' satisfaction with waiting time. The basic form of the model is $y=y_{0}+A e^{-x / t}$ where $y_{0}, A$, and $t$ are the calibration parameters.

Because every satisfaction grade value is selected at will, the model parameters are not unique. The calibration parameters will change with different satisfaction value intervals. However, the model form is unique, no matter how to assign a value, the relationship between perceived waiting time and passenger satisfaction follows a decreasing exponential distribution.

With the exponential distribution model, the sample data were fitted again, the result of data fitting is shown in Figure 2.

When the assignment interval of passenger satisfaction with waiting time is $(-25,25)$, passenger waiting satisfaction is described in Equation 2:

$y=-25.79+50.90 e^{-T / 11.57}$

where is the value of passenger waiting satisfaction; is the perceived waiting time, min.

As shown in Figure 2, six demarcated points (A, B, $C, D, E$ and $F$ ) in the horizontal coordinate axis demonstrate satisfaction value of $25,15,5,-5,-15,-25$ for the waiting time, respectively. That is, the time interval between A and B indicates the "very satisfied" region in this model.

\subsection{Model characteristics and significance}

As shown in Figure 2, when the perceived waiting time increases, passenger satisfaction with waiting decreases and their waiting mood deteriorates.
When passenger satisfaction is "very satisfied" or "satisfied" the approximate range of the corresponding perceived waiting time interval is $(A, C)$; when passengers' waiting satisfaction is "very dissatisfied" or "dissatisfied" the approximate range of the corresponding perceived waiting time is $(D, F)$. The latter range is significantly larger than the former, which indicates passengers are more likely to be dissatisfied when the perceived waiting time exceeds expectations. The trend of the part of passengers' waiting satisfaction values which is larger than 0 is obviously steeper than when the part of the satisfaction value is less than 0 , which explains that passengers moods with short waiting time are more sensitive than with longer waiting time.

Satisfaction can be divided into two levels (satisfied and dissatisfied) with the dividing point 0. In Equation 2 , when satisfaction is 0 , the perceived waiting time is 7.87 , and this time is the borderline value for satisfaction and dissatisfaction. When the perceived waiting time is less than 7.87 minutes, passengers may be satisfied; on the contrary when it is longer than 7.87 minutes, the passengers may be dissatisfied.

In order to verify the accuracy of the borderline value, 234 samples are divided into satisfaction and dissatisfaction with the standard of 7.87 minutes, and the results are compared with the actual satisfaction level. The comparison results are shown in Table 4.

Taking the reference point of 7.87 minutes as the standard, the number of "satisfaction" responses is 101 , and out of these, there were 71 of "satisfaction" in the actual survey, so when satisfaction is positive (larger than 0), the accuracy is $70.30 \%$. When satisfaction is negative (less than 0), the accuracy is $82.71 \%$, which is larger than it is positive. That is probably because the range of perceived waiting time for

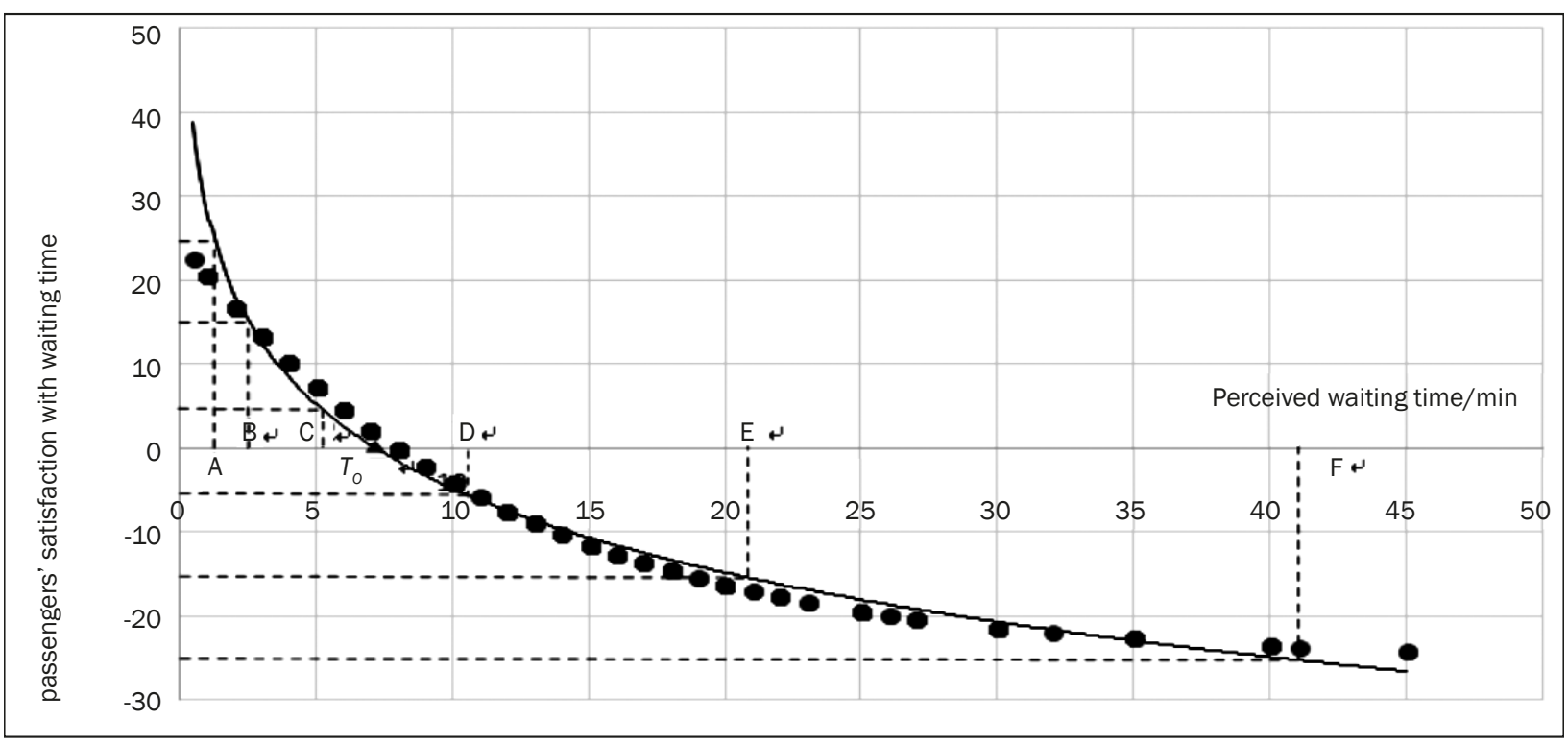

Figure 2 - Results of data fitting 
negative satisfaction is significantly larger than that of positive satisfaction, so the number of passengers in the negative satisfaction group is larger than in the positive satisfaction group.

\section{CONCLUSION}

This study found that passengers perceived waiting time is in positive correlation with "trip purpose," "riding frequency," "waiting mood," "waiting time interval," and "reserved waiting time" and is in negative correlation with "having a timing device," "presence of a companion," and "waiting behaviour". The perceived waiting time can be further improved according to these influencing factors; moreover, the perceived waiting time directly affects the passenger satisfaction with waiting time. The perceived waiting time and passenger satisfaction follow the exponential distribution, the passenger waiting satisfaction decreases as perceived waiting time increases. With this model, taking 7.87 minutes as the critical point, when the perceived waiting time is less than 7.87 minutes, the passenger is satisfied, while when the perceived waiting time is longer, the passenger is dissatisfied. And the proportion of the model results consistent with sample is $70.30 \%$ when passenger satisfaction is satisfied, while the proportion is $82.71 \%$ when the passenger satisfaction is dissatisfied.

Passenger satisfaction with the waiting time directly affects the evaluation of bus service. In order to increase the attractiveness of public transportation, it is essential to improve passenger satisfaction. Thus, the key is to reduce passengers' perceived waiting time. According to the perceived waiting time model, if passengers are in a good mood and choose positive waiting behaviour, such as the use of portable electronic devices or peer communication, the perceived waiting time will be reduced. A timing device can also reduce the perceived waiting time. Managers can improve the service level of public transportation by providing real-time information or facilities equipped to measure time at the stop. Thus, passenger satisfaction with waiting time and the evaluation of the service quality of public transportation can be improved.

This study still has some limitations. Factors of perceived waiting time are not comprehensive, sample size is limited and sample structure remains to be improved, etc.

In this paper, the perceived waiting time model did not consider the impact of real-time information, and some scholars have suggested that passenger perceived waiting time is likely to be equal to actual waiting time when real-time information is available [2]. In addition, the relationships among perceived waiting time, waiting satisfaction, and the choice of travel mode is a direction for future research.

\section{ACKNOWLEDGEMENT}

This work was financially supported by a grant from the National High Technology Research and Development Program of China (863 Program, No. 2014AA110304).

\section{公交乘客感知等待时间的影响因素及其与等车满意} 度之间的关系

\section{树民 冯, 海月 吴*，祥龙 孙，振宁 李}

\section{(哈尔滨工业大学 交通科学与工程学院, 黑龙江} 哈尔滨, 150090)

摘要: 为了定量分析影响感知等待时间的各方 面因素, 选用多元线性回归模型进行分析。以黑龙 江省哈尔滨市无实时信息提示公交站点调查得到的 234个样本数据为基础, 构建了感知等待时间影响 因素模型。结果显示出行目的、有同行的伙伴、有 时间计量工具、出行频率和候车行为感知等待时间 有显著影响, 这和现有的其他学者的研究一致。而 现有的研究中并没有涉及到候车情绪和预留等待时 间, 本文研究发现这两个因素与感知等待时间也具 有显著相关性。与现有研究成果不一致的是, 候车 时段与感知等待时间负相关, 年龄、职业等乘客自 身的社会经济属性指标并不具有显著相关性。同时 本文研究发现感知等待时间与乘客等车满意度服从 负指数分布, 并且满意度大于 0 时的变化趋势明显 陡于满意度小于 0 的部分, 这说明乘客在候车时间 较短时情绪更加敏感。本文发现等车时间为 7.87 分 钟是划分满意度正负的分界值, 当感知等待时间小 于 7.87 分钟时, 满意度为正; 当感知等待时间大于 7.87 分钟时, 满意度为负。

关键词: 感知等待时间; 多元线性回归模型; 等 车满意度; 临界感知等待时间

\section{REFERENCES}

[1] Psarros I, Kepaptsoglou K, Karlaftis MG. An empirical investigation of passenger wait time perceptions using hazard-based duration models. Journal of Public Transportation. 2011;14(3):109-122. doi: http://dx. doi.org/10.5038/2375-0901.14.3.6

[2] Mishalani RG, McCord MM, Wirtz J. Passenger wait time perceptions at bus stops: Empirical results and impact on evaluating real-time bus arrival information. Journal of Public Transportation. 2006;9(2):89-106. doi: http://dx.doi.org/10.5038/2375-0901.9.2.5

[3] Tyrinopoulos Y, Antoniou C. Public transit user satisfaction: Variability and policy implications. Transport Policy. 2008;15(4):260-272. doi:10.1016/j.tranpol.2008.06.002

[4] Eboli L, Mazzulla G. A methodology for evaluating transit service quality based on subjective and objective measures from the passenger's point of view. Transport Policy. 2011;18(1):172-181. doi:10.1016/j.tranpol.2010.07.007

[5] Hensher DA. Hierarchical stated response designs and estimation in the context of bus user preferences: a case study. Transportation Research Board; 1989-1; Washington, D.C.; 2012. 
[6] Hensher DA, Stopher P, Bullock P. Service quality-developing a service quality index in the provision of commercial bus contracts. Transportation Research Part A: Policy and Practice. 2003;37(6):499-517. doi:10.1016/S0965-8564(02)00075-7

[7] Wen $\mathrm{CH}$, Lan LW, Chen $\mathrm{CH}$. Passengers perception on service quality and their choice for intercity bus services. Transportation Research Board, 84th Annual Meeting; Washington, D.C.; 2005.

[8] Das S, Pandit D. Importance of user perception in evaluating level of service for bus transit for a developing country like India: a review. Transport Reviews. 2013;33(4):402-420. doi: 10.1080/01441647.2013.789571

[9] Daskalakis NG, Stathopoulos A. Users' perceptive evaluation of bus arrival time deviations in stochastic networks. Journal of Public Transportation. 2008;11(4):25-38. doi: http://dx.doi. org/10.5038/2375-0901.11.4.2

[10] Friman M, Gärling T. Frequency of negative critical incidents and satisfaction with public transport services. II. Journal of Retailing and Consumer Services. 2001;8(2):105-114. doi:10.1016/S09696989(00)00004-7

[11] van Hagen M, Galetzka M, Pruyn A. Perception and evaluation of waiting times at stations of Netherlands Railways (NS). Proceedings of the European Transport Conference 2007; 2007 Oct 17-19; Leiden, The Netherlands; 2008.

[12] Watkins KE, Ferris B, Borning A, et al. Where Is My Bus? Impact of mobile real-time information on the perceived and actual wait time of transit riders. Transportation Research Part A: Policy and Practice. 2011;45(8):839-848. doi:10.1016/j.tra.2011.06.010

[13] Hui MK, Alan CT, Zhou L. Interaction between two types of information on reactions to delays. Marketing Letters. 2006;17(2):151-162. doi: 10.1007/s11002006-5927-3

[14] Ohmori N, Hirano T, Harata N, et al. Passengers' waiting behavior at bus stop. Traffic and Transportation Studies: Proceedings of ICTTS 2004; 2004 Aug 2-4; Dalian, PR China. 